\title{
Article
}

\section{The Shiga Toxin Receptor Globotriaosylceramide as Therapeutic Target in Shiga Toxin E. coli Mediated HUS}

\author{
Wouter J. C. Feitz ${ }^{1,2}$, Romy Bouwmeester ${ }^{1,2}$, Thea J. A. M. van der Velden ${ }^{1}$, Susan Goorden ${ }^{3}$, Christoph Licht ${ }^{4}($, \\ Lambert P. J. W. van den Heuvel ${ }^{1,2,5,6,+}$ and Nicole C. A. J. van de Kar 1,2,*,+ (D) \\ 1 Department of Pediatrics, Amalia Children's Hospital, Radboudumc, 6525 GA Nijmegen, The Netherlands; \\ wouter.feitz@radboudumc.nl (W.J.C.F.); romy.bouwmeester@radboudumc.nl (R.B.); \\ thea.vandervelden@radboudumc.nl (T.J.A.M.v.d.V.); bert.vandenheuvel@radboudumc.nl (L.P.J.W.v.d.H.) \\ 2 Department of Pediatric Nephrology, Amalia Children's Hospital, Radboud Institute for Molecular Life \\ Sciences, Radboudumc, 6525 GA Nijmegen, The Netherlands \\ 3 Laboratory Genetic Metabolic Diseases, Department of Clinical Chemistry, Amsterdam UMC, \\ University of Amsterdam, 1105 AZ Amsterdam, The Netherlands; s.m.goorden@amsterdamumc.nl \\ 4 Department of Pediatric Nephrology, The Hospital for Sick Children, Toronto, ON M5G 1X8, Canada; \\ Christoph.licht@sickkids.ca \\ 5 Department of Pediatric Nephrology, Academic Hospitals Leuven, 3000 Leuven, Belgium \\ 6 Department of Development and Regeneration, Academic Hospitals Leuven, 3000 Leuven, Belgium \\ * Correspondence: Nicole.vandekar@radboudumc.nl; Tel.: +31-24-361-4430 \\ + These authors contributed equally to this work.
}

check for updates

Citation: Feitz, W.J.C.; Bouwmeester, R.; van der Velden, T.J.A.M.; Goorden, S.; Licht, C.; van den Heuvel, L.P.J.W.; van de Kar, N.C.A.J. The Shiga Toxin Receptor Globotriaosylceramide as Therapeutic Target in Shiga Toxin E. coli Mediated HUS. Microorganisms 2021, 9, 2157. https://doi.org/ 10.3390/microorganisms 9102157

Academic Editor: Michael E. Konkel

Received: 10 September 2021

Accepted: 12 October 2021

Published: 16 October 2021

Publisher's Note: MDPI stays neutral with regard to jurisdictional claims in published maps and institutional affiliations.

Copyright: (c) 2021 by the authors. Licensee MDPI, Basel, Switzerland. This article is an open access article distributed under the terms and conditions of the Creative Commons Attribution (CC BY) license (https:// creativecommons.org/licenses/by/ $4.0 /)$.
Abstract: In 90\% of the cases, childhood hemolytic uremic syndrome (HUS) is caused by an infection with the Shiga toxin (Stx) producing E. coli bacteria (STEC-HUS). Stx preferentially binds to its receptor, the glycosphingolipid, globotriaosylceramide (Gb3), present on the surface of human kidney cells and various organs. In this study, the glycosphingolipid pathway in endothelial cells was explored as therapeutic target for STEC-HUS. Primary human glomerular microvascular endothelial cells (HGMVECs) and human blood outgrowth endothelial cells (BOECs) in quiescent and activated state were pre-incubated with Eliglustat (Cerdelga ${ }^{\circledR}$; glucosylceramide synthase inhibitor) or Agalsidase alpha (Replagal ${ }^{\circledR}$; human cell derived alpha-galactosidase) in combination with various concentrations of Stx2a. Preincubation of endothelial cells with Agalsidase resulted in an increase of $\alpha$-galactosidase activity in the cell, but had no effect on the binding of Stx to the cell surface when compared to control cells. However, the incubation of both types of endothelial cells incubated with or without the pro-inflammatory cytokine TNF $\alpha$ in combination with Eliglustat resulted in significant decrease of Stx binding to the cell surface, a decrease in protein synthesis by Stx2a, and diminished cellular Gb3 levels as compared to control cells. In conclusion, inhibition of the synthesis of Gb3 may be a potential future therapeutic target to protect against (further) endothelial damage caused by Stx.

Keywords: STEC-HUS; shiga toxin; endothelial cells; globotriaosylceramide; glucosylceramide synthase; eliglustat

\section{Introduction}

The most frequent form of HUS in childhood is caused by a gastro-intestinal infection with the Shiga toxin (Stx) producing E. coli bacteria (STEC) [1]. For STEC-HUS, characterized by thrombocytopenia, nonimmune hemolytic anemia, and acute kidney failure [2], no specific therapy is yet available [3,4]. Patients are treated with supportive therapy alone. The disease can lead to end stage renal disease (ESRD) and has a mortality rate of $2-5 \%$ in the acute phase [5]. Long-term renal sequelae like hypertension, proteinuria, and chronic kidney failure are reported in an estimated $25-30 \%$ of cases [5].

After intestinal colonization by STEC, Stx is released into the intestinal lumen and translocated to the blood circulation. Various studies have shown that the toxin might bind to blood cells (i.e., leukocytes, red blood cells, and/or platelets) and/or to microvesicles 
that originate from those blood cells [6-9]. Bound Stx travels to its principal receptor globotriaosylceramide $(\mathrm{Gb} 3)$, located on the surface of various cells including erythrocytes, brain endothelial cells, and human kidney cells like glomerular endothelial cells and podocytes [10-16]. Uptake by endocytosis takes place, leading to protein synthesis inhibition and cell death [17].

Gb3 belongs to the group of (glyco)sphingolipids. They are structurally and functionally diverse molecules important for cell homeostasis [18]. Next to the modulation of cell-cell interactions, they are able to regulate differentiation, proliferation, and programmed cell death. The backbone of all complex glycosphingolipids is the lipid moiety ceramide [19]. Generation of ceramide takes place de novo in the endoplasmic reticulum (ER) and a plurality of glycosyltransferases and glycosidases are involved in the synthesis towards Gb3, and vice versa for the breakdown of Gb3 into ceramide [19] (Figure 1).

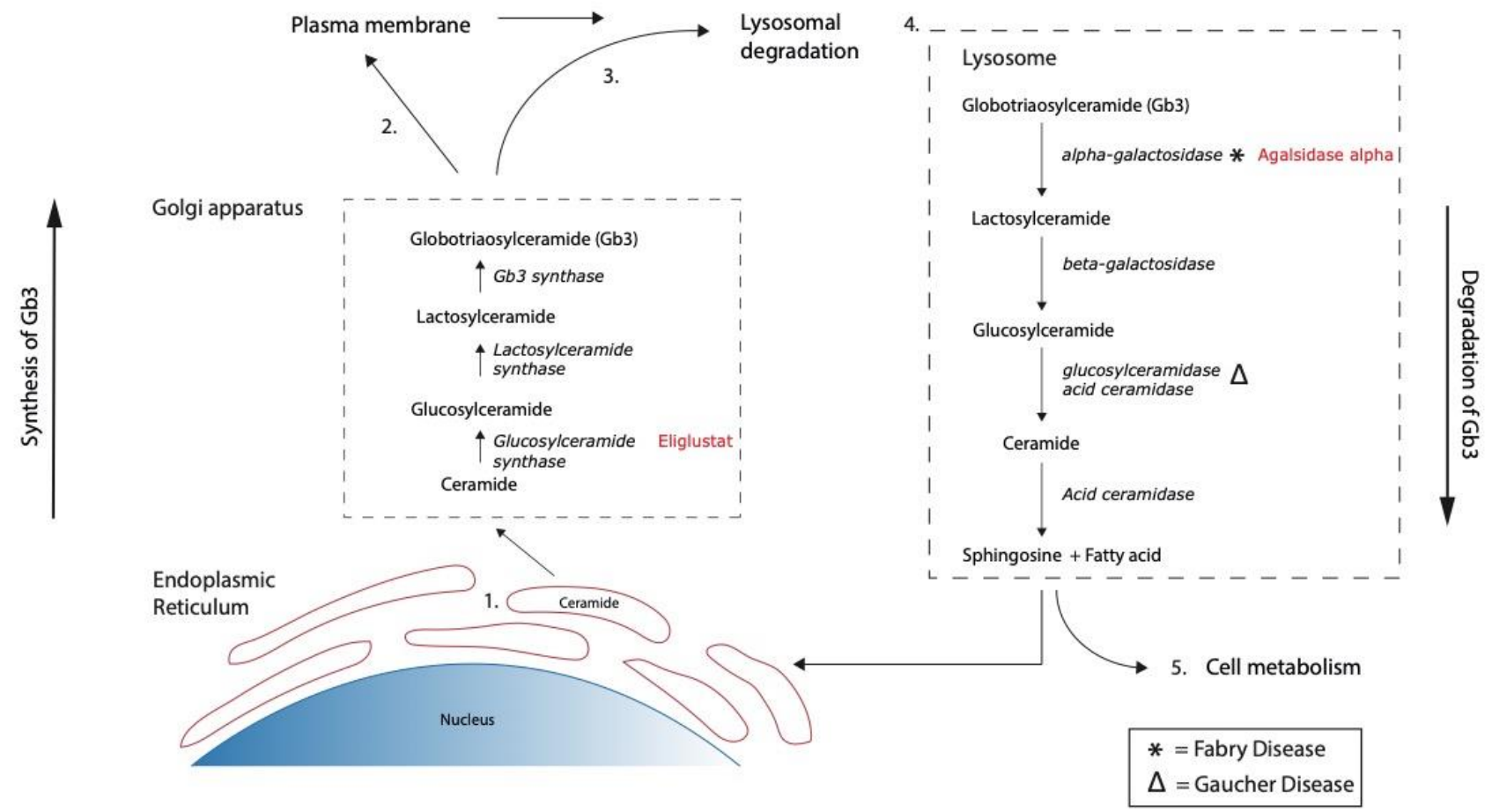

Figure 1. Schematic representation of the synthesis from ceramide to globotriaosylceramide (Gb3) and the breakdown of $\mathrm{Gb} 3$ to ceramide with the different specific enzymes involved. Ceramide travels from the endoplasmic reticulum to the Golgi apparatus, where a plurality of specific enzymes regulates further metabolism (1). After synthesis, Gb3 travels to the plasma membrane, where it resides (2) or travels to lysosomes for degradation by specific enzymes $(3,4)$. Breakdown products are re-used for glycosphingolipid synthesis (5) or function in cell metabolism processes. ${ }^{*}$ and $\Delta$ refer to the enzymes affected in Fabry disease (deficiency of alpha-galactosidase) and Gaucher disease (deficiency of glucosylceramidase), respectively. Eliglustat inhibits glucosylceramide synthase, while Agalsidase alpha substitutes alpha-galactosidase.

Gb3 has not only a central role in the pathophysiology of STEC-HUS, but it also plays a pivotal role in Fabry disease. Fabry disease is a X-linked lysosomal storage disorder with pathogenic accumulation of Gb3 caused by deficiency of the enzyme alphagalactosidase [20]. Treatment of Fabry disease focuses on replacement of alpha-galactosidase activity by substitution of the enzyme with as main principle increased breakdown of Gb3, leading to reduced storage inside the cell. Substitution of human alpha-galactosidase is clinically available as enzyme replacement therapy (ERT) and has shown clinical benefit in a subset of patients [21] (Figure 1). In addition, Gaucher disease is a rare autosomal recessive lipid storage disease caused by deficiency of glucosylceramidase (also referred to as glucocerebrosidase), resulting in accumulation of glucosylceramide, one of the precursors of Gb3 [22]. Patients with Gaucher disease are (besides ERT) treated with so-called 
substrate reduction therapy (SRT) using inhibitors of glucosylceramide synthase [23,24] (Figure 1).

Enzyme replacement therapies as well as substrate reduction therapies might be of interest in the treatment of STEC-HUS as Gb3 plays an important role in the pathophysiology. Recent in vitro studies have shown the ability of the substrate reduction inhibitor Eliglustat $\left(\right.$ Cerdelga $\left.^{\circledR}\right)$ to decrease the sensitivity for Stx in human colonic epithelial cells and human renal tubular epithelial cells $[25,26]$. Eliglustat inhibits glucosylceramide synthase activity and, thus, de novo formation of Gb3 (Figure 1) [23]. The gastro-intestinal tract and kidneys are the main affected organs in STEC-HUS with acute renal failure as one of the symptoms due to the thrombotic microangiopathic processes seen in the glomeruli of the kidney. The purpose of this research was the investigation of the effect of Eliglustat and Agalsidase alpha (Replagal ${ }^{\circledR}$, a human derived alpha galactosidase compound that stimulates breakdown of Gb3 in the cell) on human (glomerular) endothelial cells and the consequences for the interactions with Stx.

Primary human glomerular microvascular endothelial cells (HGMVECs) and human blood outgrowth endothelial cells (BOECs) were used in our studies. The effect of Eliglustat and Agalsidase alpha on cellular Gb3 levels, Stx binding to its receptor Gb3 on the cell surface, and the effect of Stx on protein synthesis was examined with liquid chromatographymass spectrometry (LC-MS), flow cytometry, and a protein synthesis assay.

\section{Materials and Methods}

\subsection{Cell Culture}

Primary human glomerular microvascular endothelial cells (HGMVECs) from four healthy adult donors were collected. The isolation and purification of HGMVECs was carried out as previously described [15]. Cells with 80-100\% confluency, passage 5-11, were used for experiments and grown in 1\% gelatin/distilled water (Sigma Aldrich, St. Louis, MI, USA) coated cell culture plates (Corning Incorporated, Kennebunk, ME, USA). Human blood outgrowth endothelial cells (BOECs) from three healthy adult donors were isolated and characterized according to established procedures [27,28]. Cells with 80-100\% confluency, passage 4-6, were used for experiments and grown in cell culture plates coated with collagen type 1 (Corning Discovery Labware, Bedford, MA, USA).

\subsection{Reagents}

Shiga toxin subtype 2a (Stx2a) was ordered from Phoenix Lab (Tufts Medical Center, Boston, MA, USA). The amount of LPS remaining in these preparations was determined to be less than $0.10 \mathrm{U} / \mathrm{mL}$. Alexa 488 labeled Shiga toxin subunit B (Stx-B) was provided by C. Lingwood (The Hospital for Sick Children, Toronto, ON, Canada). Agalsidase alpha $\left(\right.$ Replagal $^{\circledR}$ ) was a gift from C. Hollak (Amsterdam Medical Centre, Amsterdam, The Netherlands). Eliglustat hemitartrate was ordered from Cayman Chemicals (Ann Arbor, MI, USA).

\subsection{Immunofluorescence Staining and Imaging of Bound Shiga Toxin Subunit B and CD-31}

HGMVECs and BOECs were seeded in a black 96-well plate with a clear bottom (Falcon Corning Incorporated, Corning, NY, USA). Cells were incubated with either control medium or medium with $10 \mathrm{ng} / \mathrm{mL}$ of $\mathrm{TNF} \alpha$ (Roche Diagnostics GmbH, Mannheim, Germany) for $24 \mathrm{~h}$ and fixed with $2 \%$ paraformaldehyde (PFA)/PBS (Sigma Aldrich) at room temperature for $15 \mathrm{~min}$. Mouse anti-CD31 (BD Biosciences, San Jose, CA, USA) primary and corresponding species-specific Alexa Fluor 568 were used as antibodies. Alexa 488-labeled Stx-B at a concentration of $5 \mu \mathrm{g} / \mathrm{mL}$ and the fluorescent DNA stain DAPI (Invitrogen, Carlsbad, CA, USA) were added, and images were taken with the use of a Zeiss LSM900 confocal microscope (Zeiss, Oberkochen, Baden-Württemberg, Germany). 


\subsection{Analysis of Shiga Toxin Subunit B Binding by Flow Cytometry}

HGMVECs and BOECs were pre-incubated with or without $10 \mathrm{ng} / \mathrm{mL}$ of TNF $\alpha$, $8.0 \mathrm{nM}$ of Eliglustat, or $10 \mu \mathrm{g} / \mathrm{mL}$ of Agalsidase alpha for $24 \mathrm{~h}$. After pre-incubation, cells were fixed with $0.5 \%$ PFA/PBS for $5 \mathrm{~min}$ at room temperature. Next, cells were incubated with Alexa 488-labeled Stx-B at a concentration of $5 \mu \mathrm{g} / \mathrm{mL}$ and stored for $30 \mathrm{~min}$ at $4{ }^{\circ} \mathrm{C}$, protected from light. After $30 \mathrm{~min}$., cells were trypsinized with $0.05 \%$ Trypsin-EDTA (Gibco Thermo Fisher Scientific, Waltham, MA, USA), suspended in 10\% FBS/PBS (Gibco Thermo Fisher Scientific), spun down by centrifugation, and resuspended in 0.1\% BSA/PBS (Sigma Aldrich). Read out was done with the use of a CytoFlex Flow Cytometer (Beckman Coulter, Brea, CA, USA).

\subsection{Protein Synthesis by Radiolabeled ${ }^{3} H$-Leucine Incorporation Assay}

HGMVECs and BOECs were pre-incubated with or without TNF $\alpha$, Eliglustat, or Agalsidase alpha as described above. After $24 \mathrm{~h}$, Stx2a in a concentration of $1 \mathrm{nM}$ or $10 \mathrm{nM}$ together with ${ }^{3} \mathrm{H}$-leucine (PerkinElmer, Boston, MA, USA) for $24 \mathrm{~h}$ was added. In another condition, cells were pre-incubated with or without TNF $\alpha$ for $24 \mathrm{~h}$. Next, cells were incubated with Eliglustat together with Stx2a and ${ }^{3} \mathrm{H}$-leucine at the same time for $24 \mathrm{~h}$. The ${ }^{3} \mathrm{H}$-leucine incorporation assay was performed as established in the past [28].

\subsection{Cellular Gb3 and Ceramide Levels by Liquid Chromatography-Mass Spectrometry}

HGMVECs and BOECs were pre-incubated with or without $10 \mathrm{ng} / \mathrm{mL}$ of TNF $\alpha$, $8.0 \mathrm{nM}$ of Eliglustat, or $10 \mu \mathrm{g} / \mathrm{mL}$ of Agalsidase alpha for $24 \mathrm{~h}$. After incubation, cell pellets were collected and stored at $-80^{\circ} \mathrm{C}$ until further use. The analysis of cellular Gb3 and ceramide levels was performed with liquid chromatography-mass spectrometry (LC-MS). Sphingosine and d7-sphingosine were obtained from Avanti Polar Lipids Inc. (Alabaster, AL, USA) and all organic solvents were obtained from Biosolve (Valkenswaard, The Netherlands). Formic acid, butanol, and hydrochloric acid were obtained from Merck (Darmstadt, Germany), and sodium hydroxide and ammonium formate were from Sigma Aldrich. Cell pellets were dissolved in $200 \mu \mathrm{L}$ water and sonicated at 8.5-Watt output for $7 \mathrm{~s}$. The protein concentration was determined using a BCA-based assay. The metabolites were extracted from cell homogenates by a modification of the method of Bligh and Dyer [29]. Briefly, $600 \mu \mathrm{L}$ methanol, $600 \mu \mathrm{L}$ chloroform, and $450 \mu \mathrm{L}$ water was added to $150 \mu \mathrm{L}$ homogenate. Next, the lower phase $(500 \mu \mathrm{L})$ was transferred to a microwave tube and the upper phase was washed with chloroform. The lower phase was added to the first and the combined phases were dried under a stream of nitrogen at $40^{\circ} \mathrm{C}$. The residue was dissolved in $500 \mu \mathrm{L} 0.1 \mathrm{M}$ sodiumhydroxide in methanol and samples were deacylated [30]. After this, samples were neutralized by addition of $50 \mu \mathrm{L} 0.1 \mathrm{M}$ hydrochloric acid, internal standards ( $25 \mu \mathrm{L}$ of $1 \mu \mathrm{M}$ d7-sphingosine in methanol) were added, and samples were dried and dissolved in butanol and water $(1: 1, v / v)$. After drying the butanol phase, samples were dissolved in $120 \mu \mathrm{L}$ methanol and analyzed by LC-MS/MS. Metabolites were calculated using calibration lines within the appropriate concentration range, according to the internal standard ratio method. Metabolites were separated by RP-UPLC using an Acquity I-Class UPLC with BEH C18 column, $2.1 \times 50 \mathrm{~mm}$ with $1.7 \mu \mathrm{m}$ particle size (Waters Inc., Milford, MA, USA), and detected by electrospray ionization in positive mode (ESI+) and MS/MSinstrument (Xevo TQ MS, Waters Inc., Milford, MA, USA) in multiple reaction monitoring (MRM) mode. The different glycosphingolipid species were measured after deacylation and did not contain a fatty acid anymore. A sum of all isoforms with a d18:1 and d18:2 base regardless of the fatty acid was measured and noted in this study as $\mathrm{d} 18: 1 / \mathrm{X}$ and d18:2/X. For details on the LC-MS/MS methods and settings used, see [31].

\subsection{Statistical Analysis}

Data were analyzed by unpaired Student's $t$-test or ANOVA. A $p$-value of $<0.05$ was set as statistically significant. All statistical analyses were performed using GraphPad 
Prism version 5.03 (GraphPad Software, La Jolla, CA, USA) or SPSS (IBM, Amsterdam, The Netherlands). Data are expressed as mean \pm SEM.

\section{Results}

3.1. The Effect of Eliglustat and Agalsidase Alpha on Shiga Toxin Binding to the Endothelial Cell Surface

Binding of Stx to the endothelial cell surface was determined by flow cytometry in combination with fluorescent labelled Shiga toxin subunit B (Stx-B) in order to indirectly measure Gb3 cell surface expression levels (20). TNF $\alpha$ was used as positive control, as $\mathrm{TNF} \alpha$ is a pro-inflammatory cytokine known to upregulate Gb3 expression on the cell surface by increasing the activity of enzymes involved in the Gb3 precursor synthesis (Figure 2) [32,33].

a.
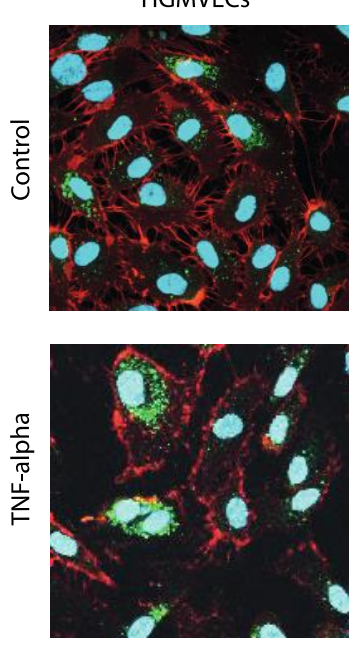

BOECS
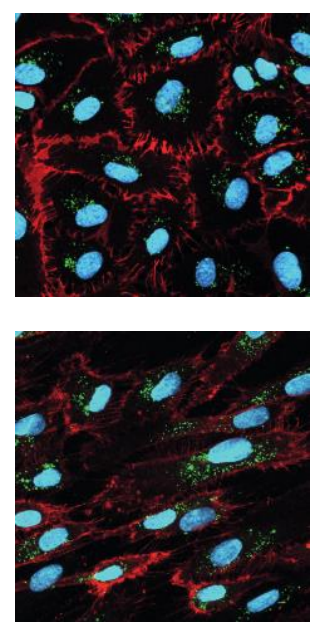

b.

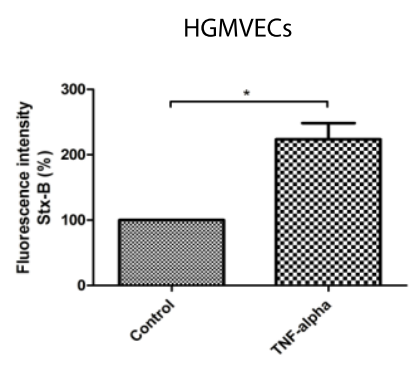

c.

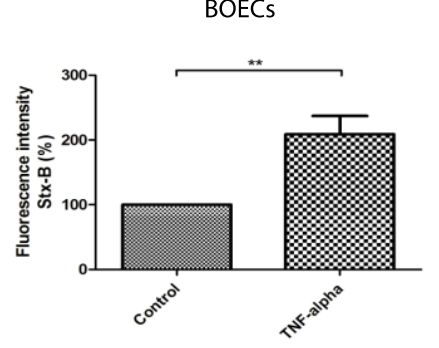

Figure 2. The expression and binding of Alexa 488 labelled Shiga toxin subunit B (Stx-B) on the cell surface of primary HGMVECs and BOECs. (a) Immunofluorescent images of Stx-B on HGMVECs and BOECs pre-incubated without (control) or with $10 \mathrm{ng} / \mathrm{mL}$ of TNF $\alpha$ for $24 \mathrm{~h}$. Stx-B in green and CD-31 in red. The nucleus is stained in blue; $400 \times$ Magnification by confocal microscopy. Flow cytometry of the binding of Stx-B on the cell surface of (b) primary HGMVECs or (c) BOECs pre-incubated without (control) or with $10 \mathrm{ng} / \mathrm{mL}$ of TNF $\alpha$ for $24 \mathrm{~h}$. Pre-incubation of TNF $\alpha$ resulted in an increase of Stx-B binding on the endothelial cell surface of both HGMVECs and BOECs. Statistically significant differences are indicated with single $(p<0.05)$ or double $(p<0.01)$ characters, respectively.

Primary HGMVECs from four healthy donors were incubated with or without $10 \mathrm{ng} / \mathrm{mL} \mathrm{TNF} \alpha, 8.0 \mathrm{nM}$ of Eliglustat, or $10 \mu \mathrm{g} / \mathrm{mL}$ of Agalsidase alpha for $24 \mathrm{~h}$. The concentrations and incubation times used for these experiments were determined by flow cytometry titration curves (data not shown) or established before [34]. Agalsidase alpha had no significant effect on Stx-B binding to the cellular surface, while the binding decreased by $56 \%$ in cells incubated with Eliglustat in comparison to the control group (Figure 3a). An even stronger effect was obtained when primary HGMVECs were incubated with TNF $\alpha$ in combination with Eliglustat. TNF $\alpha$ in combination with Eliglustat for $24 \mathrm{~h}$ resulted in a decrease of Stx-B binding by $79 \%$ as compared to the control group treated with TNF $\alpha$ solely (Figure 3a).

To study if the effect of Eliglustat was endothelial cell type specific, another endothelial cell type was used for these experiments. Human derived BOECs from three different donors were incubated with $8.0 \mathrm{nM}$ of Eliglustat for $24 \mathrm{~h}$. Incubation with Eliglustat alone resulted in a decrease of Stx-B binding on the cell surface by $47 \%$ (Figure $3 b$ ). When BOECs were incubated with $10 \mathrm{ng} / \mathrm{mL}$ of TNF $\alpha$ in combination with $8.0 \mathrm{nM}$ of Eliglustat for $24 \mathrm{~h}$, 
Stx-B binding decreased by approximately $72 \%$ compared to BOECs pre-incubated with $10 \mathrm{ng} / \mathrm{mL}$ of TNF $\alpha$ for $24 \mathrm{~h}$ alone (Figure $3 \mathrm{~b}$ ).

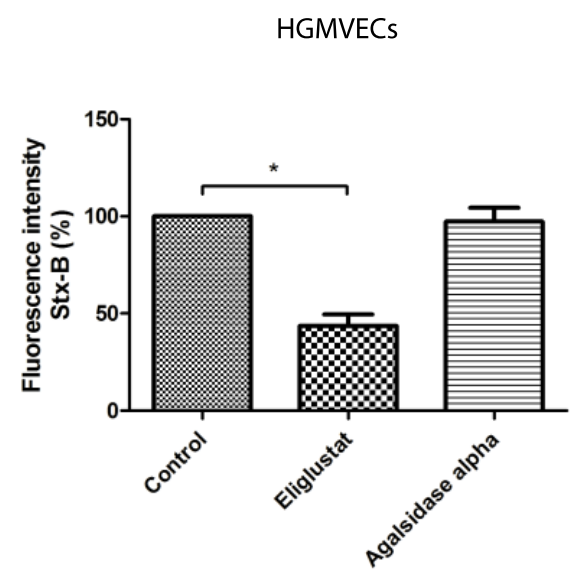

b.

BOECS

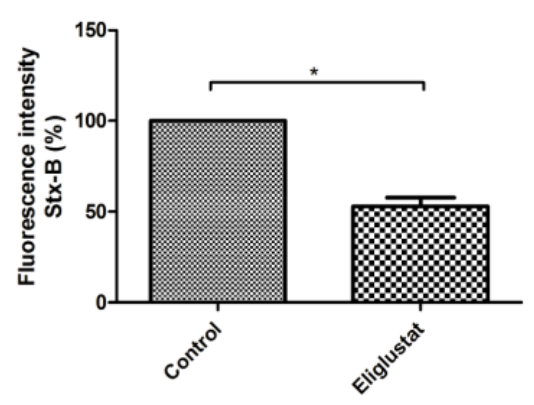

HGMVECS + TNF-alpha

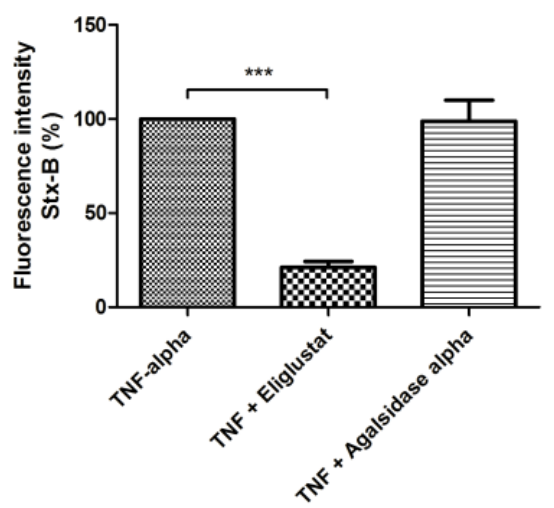

BOECs + TNF-alpha

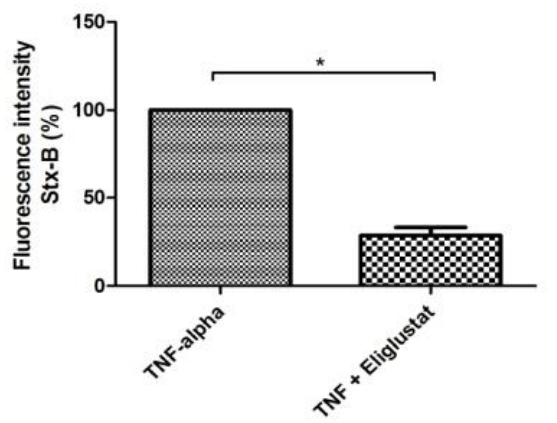

Figure 3. The binding of Alexa 488 labelled Stx-B to the cell surface of primary HGMVECs or BOECs. Binding of Stx-B to the cell surface of (a) HGMVECs or (b) BOECs incubated with or without TNF $\alpha$ in combination with or without $8.0 \mathrm{nM}$ Eliglustat or $10 \mu \mathrm{g} / \mathrm{mL}$ of Agalsidase alpha for $24 \mathrm{~h}$. Read out performed with the use of flow cytometry. Statistically significant differences are indicated with single $(p<0.05)$ or triple $(p<0.001)$ characters, respectively.

\subsection{The Effect of Eliglustat and Agalsidase Alpha on Protein Synthesis Inhibition by Stx2a in Endothelial Cells}

Uptake of Stx into the cell by endocytosis resulted in the inhibition of protein synthesis and cell death [17]. As we detected a markedly reduced Stx-B binding to the endothelial cell surface after incubation with Eliglustat, we investigated the effect of (especially) Eliglustat on endothelial protein synthesis inhibition by Stx2a.

Primary HGMVECs were pre-incubated with or without TNF $\alpha$, Eliglustat, or Agalsidase alpha for $24 \mathrm{~h}$. Next, cells were incubated with 1.0 or $10 \mathrm{nM}$ of Stx2a for $24 \mathrm{~h}$, and the effect on protein synthesis was examined with a ${ }^{3} \mathrm{H}$-leucine incorporation assay [28].

Stx2a inhibited protein synthesis in HGMVECs in a concentration dependent manner with inhibition by $18 \%$ for $1.0 \mathrm{nM}$ of Stx2a and by $30 \%$ for $10 \mathrm{nM}$ of Stx2a (Figure $4 \mathrm{a}-$ Control). Pre-incubation with $10 \mathrm{ng} / \mathrm{mL}$ of TNF $\alpha$ for $24 \mathrm{~h}$ increased the inhibition of protein synthesis by Stx2a (Figure $4 \mathrm{~b}-\mathrm{TNF} \alpha$ ), while pre-incubation with Eliglustat protected cells from protein synthesis inhibition caused by Stx2a (Figure 4a). A marginal effect was observed with Agalsidase alpha, in contrast to Eliglustat, which displayed a clear protective effect for protein synthesis inhibition by Stx2a.

More importantly, when $10 \mathrm{ng} / \mathrm{mL}$ of $\mathrm{TNF} \alpha$ at the same time as Eliglustat or Agalsidase alpha was added, Eliglustat still significantly counteracted the decreased protein 
synthesis caused by Stx2a (Figure 4b). Stx2a application of $1.0 \mathrm{nM}$ for $24 \mathrm{~h}$ hardly caused any inhibition (estimated 3\%) in the TNF $\alpha+$ Eliglustat group vs. $65 \%$ when TNF $\alpha$ alone was used (Figure 4b). For 10 nM Stx $2 a$, this was 33\% vs. 87\%, respectively. Agalsidase alpha had no significant effect on protein synthesis caused by Stx2a when used in combination with $\mathrm{TNF} \alpha$ (Figure 4b).

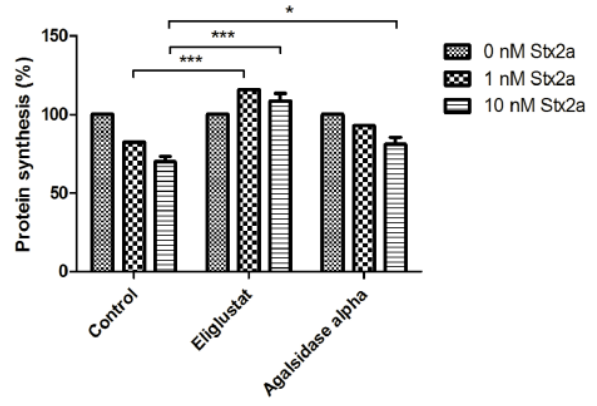

b.

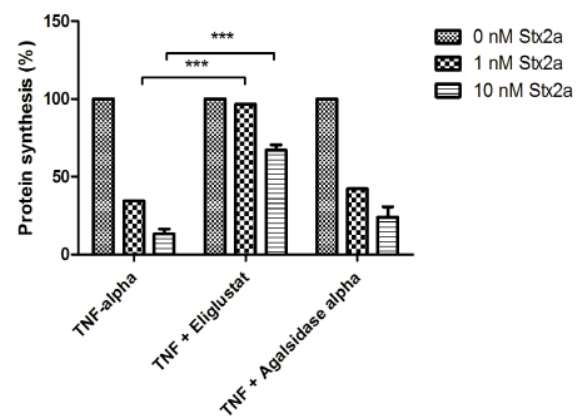

Figure 4. Protein synthesis of primary HGMVECs incubated with Stx2a for $24 \mathrm{~h}$. (a) Protein synthesis of HGMVECs pre-incubated with $8.0 \mathrm{nM}$ Eliglustat or $10 \mu \mathrm{g} / \mathrm{mL}$ Agalsidase alpha for $24 \mathrm{~h}$. After 24 h, cells were incubated with Stx2a for 24 h. (b) Protein synthesis of HGMVECs pre-incubated with 10 $\mathrm{ng} / \mathrm{mL} \mathrm{TNF} \alpha$ or TNF $\alpha$ in combination with Eliglustat or Agalsidase alpha. Statistically significant differences are indicated with single $(p<0.05)$ or triple $(p<0.001)$ characters, respectively.

Next, the effect of Eliglustat on protein synthesis in BOECs was investigated (Figure 5). Stx2a alone inhibited protein synthesis in a concentration dependent manner with $50 \%$ for $1.0 \mathrm{nM}$ and $65 \%$ for $10 \mathrm{nM}$ of Stx2a (Figure 5a-Control). Pre-incubation with $8.0 \mathrm{nM}$ of Eliglustat for $24 \mathrm{~h}$ resulted in less protein synthesis inhibition (13\%) when $1.0 \mathrm{nM} \mathrm{Stx2a}$ was used, and $28 \%$ with $10 \mathrm{nM}$ of Stx2a (Figure $5 \mathrm{a}$-Eliglustat). Pre-incubation of BOECs with $10 \mathrm{ng} / \mathrm{mL}$ of TNF $\alpha$ together with $8.0 \mathrm{nM}$ of Eliglustat caused a decrease of protein synthesis by $51 \%$ for $1.0 \mathrm{nM}$ Stx 2 a (vs. $71 \%$ for TNF $\alpha$ alone). A concentration of $10 \mathrm{nM}$ Stx $2 \mathrm{a}$ resulted in $56 \%$ protein synthesis inhibition (vs. $88 \%$ for $\mathrm{TNF} \alpha$ alone) (Figure $5 \mathrm{~b}$ ).

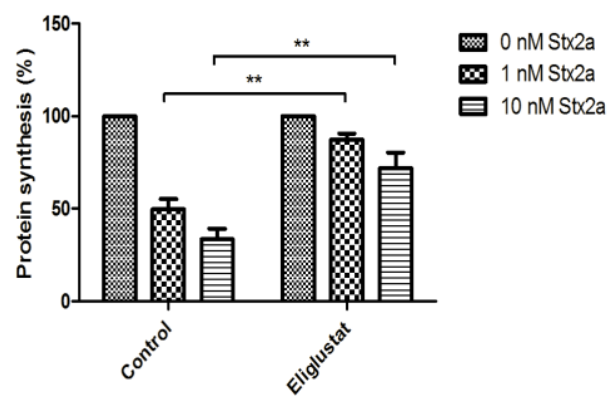

b.

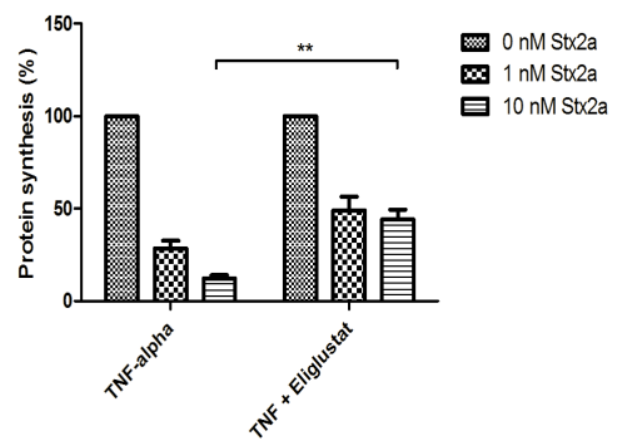

Figure 5. Protein synthesis of BOECs incubated with Stx2a for $24 \mathrm{~h}$. (a) Protein synthesis of BOECs pre-incubated with $8.0 \mathrm{nM}$ Eliglustat for $24 \mathrm{~h}$. After $24 \mathrm{~h}$, cells were incubated with Stx2a for $24 \mathrm{~h}$. (b) Protein synthesis of BOECs pre-incubated with $10 \mathrm{ng} / \mathrm{mL}$ of TNF $\alpha$ or TNF $\alpha$ in combination with Eliglustat at the same time for $24 \mathrm{~h}$. After $24 \mathrm{~h}$, cells were incubated with Stx2a for $24 \mathrm{~h}$. Statistical significant differences are indicated with double characters ( $p$-value $<0.01)$.

In summary, Eliglustat decreased the inhibition of protein synthesis caused by Stx2a in both primary HGMVECs and BOECs. 
Finally, we examined the effect of Eliglustat incubated at the same time (instead of sequentially) with Stx2a on the inhibition of protein synthesis caused in HGMVECs to study if it might be a therapeutical option for patients who are already infected with the toxin.

Primary HGMVECs from three different donors were pre-incubated with or without $10 \mathrm{ng} / \mathrm{mL}$ TNF $\alpha$ for $24 \mathrm{~h}$. Next, cells were incubated with $8.0 \mathrm{nM}$ Eliglustat together with $1.0 \mathrm{nM}$ or $10 \mathrm{nM}$ Stx2a for $24 \mathrm{~h}$ simultaneously, and protein synthesis was determined (Figure 6a). Pre-incubation of HGMVECs with TNF $\alpha$ and incubation of cells with Eliglustat in combination with $10 \mathrm{nM}$ Stx2a resulted in a clear significant decrease in protein synthesis inhibition ( $6 \%$ protein synthesis versus $61 \%$ in TNF $\alpha$ alone) (Figure $6 \mathrm{~b}$ ). In conclusion, Eliglustat also had a clear protective effect against protein synthesis inhibition caused by Stx2a when simultaneously given with the toxin.

a.

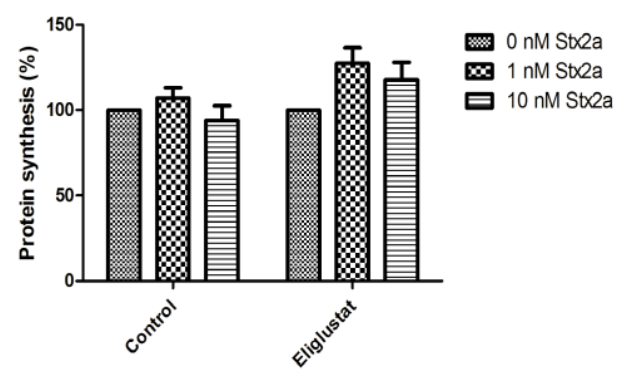

b.

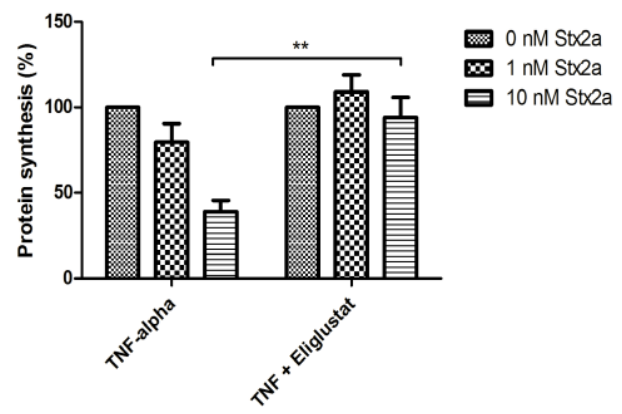

Figure 6. Protein synthesis of primary HGMVECs incubated with Eliglustat and Stx2a at the same time for $24 \mathrm{~h}$. (a) Protein synthesis of HGMVECs incubated with $8.0 \mathrm{nM}$ Eliglustat and Stx2a at the same time for $24 \mathrm{~h}$. (b) Protein synthesis of HGMVECs pre-incubated with $10 \mathrm{ng} / \mathrm{mL}$ of TNF $\alpha$ for $24 \mathrm{~h}$ and incubated with Eliglustat together with Stx2a simultaneously for $24 \mathrm{~h}$. Statistical significant differences are indicated with double characters ( $p$-value $<0.01)$.

\subsection{The Effect of Eliglustat and Agalsidase Alpha on Cellular Gb3 and Ceramide Levels}

As Agalsidase alpha showed only minor effects on Stx-B binding to the endothelial cell surface and protein synthesis inhibition caused by Stx2a, we examined the effect on cellular Gb3 and ceramide levels for both compounds. It might be the case that Agalsidase alpha has no effect on cell surface Gb3 levels, but still influences the amount of Gb3 present in the cell. In addition, lactosylceramide and glucosylceramide were measured.

Primary HGMVECs from two different donors were incubated with or without $T N F \alpha$, Eliglustat, or Agalsidase alpha for $24 \mathrm{~h}$. Cellular Gb3, lactosylceramide, glucosylceramide, and ceramide levels of the isoforms $\mathrm{d} 18: 1 / \mathrm{X}$ and $\mathrm{d} 18: 2 / \mathrm{X}$ were determined with LC-MS. The different glycosphingolipid species were measured after deacylation and did not contain a fatty acid anymore.

Incubation of cells with $10 \mathrm{ng} / \mathrm{mL}$ TNF $\alpha$ for $24 \mathrm{~h}$ increased the amount of cellular Gb3 when compared to the control group (Table 1). Decreased cellular Gb3 levels were found when HGMVECs were incubated with Eliglustat, Agalsidase alpha, or TNF $\alpha+$ Eliglustat in comparison to the control group (Table 1). Cellular ceramide levels were minimally increased in the TNF $\alpha$ alone and TNF $\alpha+$ Eliglustat cells, while slightly decreased levels were measured when HGMVECs were incubated with Eliglustat or Agalsidase alpha alone and compared to the control cells (Table 1).

Lastly, BOECs from two different donors were incubated with TNF $\alpha$ alone or TNF $\alpha$ in combination with Eliglustat for $24 \mathrm{~h}$. TNF $\alpha$ increased the amount of cellular Gb3 in comparison to the control cells (Table 1), while decreased cellular Gb3 levels were measured when cells were incubated with TNF $\alpha+$ Eliglustat vs. the control cells (Table 1). Minor 
decreased ceramide levels in BOECs were observed when incubated with TNF $\alpha$ alone or $\mathrm{TNF} \alpha+$ Eliglustat and compared to the control cells (Table 1).

Table 1. Cellular Gb3, lactosylceramide, glucosylceramide, and ceramide levels of primary HGMVECs and BOECs. HGMVECs and BOECs were incubated with or without $10 \mathrm{ng} / \mathrm{mL}$ of TNF $\alpha$, $8.0 \mathrm{nM}$ of Eliglustat, $10 \mu \mathrm{g} / \mathrm{mL}$ of Agalsidase alpha, or TNF $\alpha$ together with Eliglustat for $24 \mathrm{~h}$. Cellular Gb3, lactosylceramide, glucosylceramide, and ceramide levels of the isoforms d18:1/X and $\mathrm{d} 18: 2 / \mathrm{X}$ were determined with liquid chromatography-mass spectrometry (LC-MS). Levels of the different donors ( $\mathrm{N}=2$ for HGMVECs and $\mathrm{N}=2$ for BOECs) and two different isoforms $\mathrm{d} 18: 1 / \mathrm{X}$ and $\mathrm{d} 18: 2 / \mathrm{X}$ were averaged and standardized to the control group $(100 \%)$. Gb3 = Globotriaosylceramide; LacCer = Lactosylceramide; GlcCer = Glucosylceramide; Cer = Ceramide; .. . $=$ Not analyzed .

\begin{tabular}{ccccc}
\hline & \multicolumn{4}{c}{ HGMVECs } \\
\cline { 2 - 5 } & Gb3 (\%) & LacCer (\%) & GlcCer (\%) & Cer (\%) \\
\hline Control & 100 & 100 & 100 & 100 \\
TNF-alpha & 172 & 89 & 128 & 116 \\
Eliglustat & 74 & 59 & 49 & 88 \\
Agalsidase alpha & 64 & 68 & 75 & 93 \\
TNF + Eliglustat & 61 & 56 & 51 & 110 \\
\hline & \multicolumn{4}{c}{ BOECs } \\
\cline { 2 - 5 } & Gb3 (\%) & LacCer (\%) & GlcCer (\%) & Cer (\%) \\
\hline Control & 100 & 100 & 100 & 100 \\
TNF-alpha & 177 & 93 & 184 & n.a. \\
Eliglustat & n.a & n.a & n.a. & n.a. \\
Agalsidase alpha & n.a & n.a. & n.a. & 9. \\
TNF + Eliglustat & 79 & 65 & 84 & \\
\hline
\end{tabular}

\section{Discussion}

In this study, the ability to target the glycosphingolipid pathway as an indirect way to influence Gb3 and the sensitivity of human endothelial cells for Stx2a was investigated. Eliglustat is known as inhibitor of glucosylceramide synthase, which inhibits the formation of lactosylceramide, the precursor of Gb3, while Agalsidase alpha, replacing alpha-galactosidase activity, stimulates the lysosomal breakdown of cellular Gb3 [21,23]. Eliglustat decreased the Stx-B binding to the cell surface of both primary HGMVECs and BOECs pre-stimulated with and without the pro-inflammatory cytokine TNF $\alpha$. In addition, and more importantly, Eliglustat protected endothelial cells against the inhibition of protein synthesis when used simultaneously with Stx2a. These effects were not seen with Agalsidase alpha. Finally, Eliglustat and Agalsidase alpha both decreased the amount of cellular Gb3 (isoforms d18:1/X and d18:2/X) of primary HGMVECs and BOECs.

The difference between Eliglustat and Agalsidase alpha on Stx-B binding might be explained by the fact that Agalsidase alpha is effective in the lysosome, while in contrast, Eliglustat operates in the Golgi apparatus. Eliglustat showed minor effects on ceramide levels, which can be clarified by the fact that glucosylceramide synthase (inhibited by Eliglustat) and alpha-galactosidase (substituted by Agalsidase alpha) are active after the generation of ceramide.

In the past, Garimano et al. [25] incubated human colonic epithelial cells with Stx in combination with and without Eliglustat [25]. In line with our results, they observed a decreased entry of the toxin and a decreased cytotoxic effect on cells incubated with Eliglustat [25]. Silberstein et al. [35] investigated the effect of C-9 on human proximal tubular epithelial cells after Stx incubation. C-9, known as a potent inhibitor of glucosylceramide synthase, prevented the tubular cells from the cytotoxic effect of Stx by decreasing Gb3 levels [35]. The same group evaluated the effect of C-9 on rats injected with Stx and oral treatment with this compound reduced renal and intestinal injuries with 50\% [36]. Recently, Sanchez et al. [26] published the protective effect of Eliglustat against Stx2 in human renal 
tubular epithelial cells [26]. Pre-treatment with Eliglustat reduced Gb3 expression and prevented the effect of Stx2 on cell viability, proliferation, and apoptosis [26].

Abe et al. [37] tested the inhibitory effect of d-threo-phenyl-2-decanooylamino-3morpholino-1-propanol (PDMP) prototypes on glucosylceramide synthase in Fabry lymphocytes. Depletion of Gb3 with 70 to $80 \%$ was measured and binding of Stx-B clearly decreased [37]. In contrast to primary HGMVECs and BOECs, lymphocytes derived from Fabry patients have accumulated Gb3 and, with this in mind, it is hard to compare our results with results from this study. However, Eliglustat is not the only SRT available for patients with lipid storage disorders. Girard et al. [38] showed the protective effect of Miglustat against Stx in human glomerular endothelial cells and proximal tubular epithelial cells. Reduced cell death, intracellular edema, and cell detachment were noticed and a decrease in Gb3 expression was shown. Interestingly, pre-treatment with Miglustat for $48 \mathrm{~h}$ caused a significant protection compared to $24 \mathrm{~h}$ of treatment [38]. As Miglustat and Eliglustat both inhibit glucosylceramide synthase, it is expected that Miglustat has similar effects on primary HGMVECs and BOECs. Both compounds are FDA approved for the treatment of glycosphingolipid storage disorders and might be good treatment options for STEC-HUS; however, the reported side effects of both compounds makes Eliglustat probably more favorable for clinical use in patients with STEC-HUS $[39,40]$.

In contrast to the studies described with Eliglustat above, the in vitro experiments in our study were carried out with primary human glomerular endothelial cells. As (glomerular) endothelial damage is seen as one of the central hallmarks of the thrombotic microangiopathy seen in STEC-HUS, it is of great value to understand the effects of Eliglustat in combination with Stx2a for the human glomerular endothelium. Primary isolated glomerular endothelial cells were used, which have the advantage of not being genetically altered and are the closest representative for one of the main cell types involved and damaged in HUS patients. Lastly, cells were activated with the cytokine $\mathrm{TNF} \alpha$, a pro-inflammatory cytokine present during disease activity, and the combination of TNF $\alpha$ and Stx2a more closely reflects the actual situation during the acute phase of disease [41].

From a pathophysiological point of view, studying the effect of Eliglustat in the upcoming 3D glomerular on a chip model might give us a better understanding of the cellular interactions under dynamic conditions of the various glomerular cells and bring us closer to the in vivo human situation.

The best prevention for getting STEC-HUS is to avoid intake of STEC-contaminated products, but this is clearly impossible. A low inoculum of STEC can already lead to STECinfection, STEC-induced bloody diarrhea, and HUS [42,43]. However, it might be possible to inhibit or decrease the effect of Stx on the glomerular cells, tubular cells, and podocytes in the kidney once the toxin is present in the circulation. The observations in this study and recent publications by others $[25,26,35,36]$ strengthen the hypothesis that inhibition of glucosylceramide synthase and thereby blocking the formation of Gb3 may be a therapeutic strategy for future purposes. Eliglustat, given orally, has been approved by the FDA in 2014 and is already on the market for the treatment of patients with Gaucher disease [23,24]. It is metabolized in the liver and not in the kidney. No dosage adjustments have to be made in patients with kidney failure. It has the advantage that IC50 values in humans and its mild side effects like fatigue, headache, and back pain are already known [22]. Glucosylceramide synthase inhibitors such as Eliglustat could be therapeutical for STEC-infected patients with bloody diarrhea, who might develop HUS. In addition, it might be a future therapeutic to prevent renal damage in those who have already developed STEC-HUS.

Author Contributions: W.J.C.F., R.B. and T.J.A.M.v.d.V. designed and performed experiments and analyzed data; S.G. and C.L. analyzed data and edited the manuscript; L.P.J.W.v.d.H. and N.C.A.J.v.d.K. designed experiments, analyzed data, and supervised the study; W.J.C.F., L.P.J.W.v.d.H. and N.C.A.J.v.d.K. wrote the manuscript. All authors have read and agreed to the published version of the manuscript. 
Funding: Wouter Feitz was funded by the Principal Clinician Grant (Nicole C.A.J. van de Kar), Radboudumc, Nijmegen, The Netherlands.

Institutional Review Board Statement: The study was conducted according to the guidelines of the Declaration of Helsinki and approved by the Institutional Review Board of the Radboudumc, Nijmegen, The Netherlands.

Informed Consent Statement: Informed consent was obtained from all subjects involved in the study.

Data Availability Statement: Not applicable.

Acknowledgments: We thank C. Lingwood (The Hospital for Sick Children, Toronto, ON, Canada) for providing Alexa 488 labelled Stx-B. We thank C. Hollak (Amsterdam Medical Centre, Amsterdam, The Netherlands) for providing Agalsidase alfa (Replagal ${ }^{\circledR}$ ). Nicole C.A.J. van de Kar and Lambert P.J.W. van den Heuvel are members of the European Reference network for Rare Kidney Diseases (ERKNet)-Project No 739532.

Conflicts of Interest: The authors declare no conflict of interest.

\section{References}

1. Tarr, P.I.; Gordon, C.A.; Chandler, W.L. Shiga-toxin-producing Escherichia coli and haemolytic uraemic syndrome. Lancet 2005, 365, 1073-1086. [CrossRef]

2. Noris, M.; Mescia, F.; Remuzzi, G. STEC-HUS, atypical HUS and TTP are all diseases of complement activation. Nat. Rev. Nephrol. 2012, 8, 622-633. [CrossRef]

3. Spinale, J.M.; Ruebner, R.L.; Copelovitch, L.; Kaplan, B.S. Long-term outcomes of Shiga toxin hemolytic uremic syndrome. Pediatr. Nephrol. 2013, 28, 2097-2105. [CrossRef]

4. Garg, A.X.; Suri, R.S.; Barrowman, N.; Rehman, F.; Matsell, D.; Rosas-Arellano, M.P.; Salvadori, M.; Haynes, R.B.; Clark, W.F. Long-term renal prognosis of diarrhea-associated hemolytic uremic syndrome: A systematic review, meta-analysis, and meta-regression. JAMA 2003, 290, 1360-1370. [CrossRef] [PubMed]

5. Rosales, A.; Hofer, J.; Zimmerhackl, L.B.; Jungraithmayr, T.C.; Riedl, M.; Giner, T.; Strasak, A.; Orth-Höller, D.; Würzner, R.; Karch, H.; et al. Need for long-term follow-up in enterohemorrhagic Escherichia coli-associated hemolytic uremic syndrome due to late-emerging sequelae. Clin. Infect. Dis. 2012, 54, 1413-1421. [CrossRef] [PubMed]

6. Ståhl, A.L.; Arvidsson, I.; Johansson, K.E.; Chromek, M.; Rebetz, J.; Loos, S.; Kristoffersson, A.C.; Békássy, Z.D.; Mörgelin, M.; Karpman, D. A novel mechanism of bacterial toxin transfer within host blood cell-derived microvesicles. PLoS Pathog. 2015, 11, e1004619. [CrossRef] [PubMed]

7. Villysson, A.; Tontanahal, A.; Karpman, D. Microvesicle Involvement in Shiga Toxin-Associated Infection. Toxins 2017, 9, 376. [CrossRef]

8. Johansson, K.; Willysson, A.; Kristoffersson, A.C.; Tontanahal, A.; Gillet, D.; Ståhl, A.L.; Karpman, D. Shiga Toxin-Bearing Microvesicles Exert a Cytotoxic Effect on Recipient Cells Only When the Cells Express the Toxin Receptor. Front. Cell. Infect. Microbiol. 2020, 10, 212. [CrossRef]

9. Brigotti, M.; He, X.; Carnicelli, D.; Arfilli, V.; Porcellini, E.; Galassi, E.; Tazzari, P.L.; Ricci, F.; Patfield, S.A.; Testa, S.; et al. Particulate Shiga Toxin 2 in Blood is Associated to the Development of Hemolytic Uremic Syndrome in Children. Thromb. Haemost. 2020, 120, 107-120. [CrossRef]

10. Waddell, T.; Cohen, A.; Lingwood, C.A. Induction of verotoxin sensitivity in receptor-deficient cell lines using the receptor glycolipid globotriosylceramide. Proc. Natl. Acad. Sci. USA 1990, 87, 7898-7901. [CrossRef]

11. Ergonul, Z.; Hughes, A.K.; Kohan, D.E. Induction of apoptosis of human brain microvascular endothelial cells by shiga toxin 1. J. Infect. Dis. 2003, 187, 154-158. [CrossRef] [PubMed]

12. Betz, J.; Dorn, I.; Kouzel, I.U.; Bauwens, A.; Meisen, I.; Kemper, B.; Bielaszewska, M.; Mormann, M.; Weymann, L.; Sibrowski, W.; et al. Shiga toxin of enterohaemorrhagic Escherichia coli directly injures developing human erythrocytes. Cell. Microbiol. 2016, 18, 1339-1348. [CrossRef] [PubMed]

13. Legros, N.; Pohlentz, G.; Steil, D.; Müthing, J. Shiga toxin-glycosphingolipid interaction: Status quo of research with focus on primary human brain and kidney endothelial cells. Int. J. Med. Microbiol. 2018, 308, 1073-1084. [CrossRef]

14. Dettmar, A.K.; Binder, E.; Greiner, F.R.; Liebau, M.C.; Kurschat, C.E.; Jungraithmayr, T.C.; Saleem, M.A.; Schmitt, C.P.; Feifel, E.; Orth-Höller, D.; et al. Protection of human podocytes from shiga toxin 2-induced phosphorylation of mitogen-activated protein kinases and apoptosis by human serum amyloid P component. Infect. Immun. 2014, 82, 1872-1879. [CrossRef]

15. van Setten, P.A.; van Hinsbergh, V.W.; van der Velden, T.J.; van de Kar, N.C.; Vermeer, M.; Mahan, J.D.; Assmann, K.J.; van den Heuvel, L.P.; Monnens, L.A. Effects of TNF alpha on verocytotoxin cytotoxicity in purified human glomerular microvascular endothelial cells. Kidney Int. 1997, 51, 1245-1256. [CrossRef] [PubMed]

16. Locatelli, M.; Buelli, S.; Pezzotta, A.; Corna, D.; Perico, L.; Tomasoni, S.; Rottoli, D.; Rizzo, P.; Conti, D.; Thurman, J.M.; et al. Shiga toxin promotes podocyte injury in experimental hemolytic uremic syndrome via activation of the alternative pathway of complement. J. Am. Soc. Nephrol. 2014, 25, 1786-1798. [CrossRef] 
17. Lingwood, C. Verotoxin Receptor-Based Pathology and Therapies. Front. Cell. Infect. Microbiol. 2020, 10, 123. [CrossRef]

18. Iqbal, J.; Walsh, M.T.; Hammad, S.M.; Hussain, M.M. Sphingolipids and Lipoproteins in Health and Metabolic Disorders. Trends Endocrinol. Metab. 2017, 28, 506-518. [CrossRef]

19. Sandhoff, K.; Kolter, T. Biosynthesis and degradation of mammalian glycosphingolipids. Philos. Trans. R. Soc. Lond. Ser. B Biol. Sci. 2003, 358, 847-861. [CrossRef]

20. Maruyama, H.; Miyata, K.; Mikame, M.; Taguchi, A.; Guili, C.; Shimura, M.; Murayama, K.; Inoue, T.; Yamamoto, S.; Sugimura, K.; et al. Effectiveness of plasma lyso-Gb3 as a biomarker for selecting high-risk patients with Fabry disease from multispecialty clinics for genetic analysis. Genet. Med. 2019, 21, 44-52. [CrossRef]

21. Hennermann, J.B.; Arash-Kaps, L.; Fekete, G.; Schaaf, A.; Busch, A.; Frischmuth, T. Pharmacokinetics, pharmacodynamics, and safety of moss-aGalactosidase A in patients with Fabry disease. J. Inherit. Metab. Dis. 2019, 42, 527-533. [CrossRef]

22. Bennett, L.L.; Turcotte, K. Eliglustat tartrate for the treatment of adults with type 1 Gaucher disease. Drug Des. Devel. Ther. 2015, 9, 4639-4647. [CrossRef]

23. Mistry, P.K.; Lukina, E.; Ben Turkia, H.; Shankar, S.P.; Baris, H.; Ghosn, M.; Mehta, A.; Packman, S.; Pastores, G.; Petakov, M.; et al. Outcomes after 18 months of eliglustat therapy in treatment-naïve adults with Gaucher disease type 1: The phase 3 ENGAGE trial. Am. J. Hematol. 2017, 92, 1170-1176. [CrossRef]

24. Shayman, J.A. Eliglustat tartrate, a prototypic glucosylceramide synthase inhibitor. Expert. Rev. Endocrinol. Metab. 2013, 8, 491-504. [CrossRef]

25. Garimano, N.; Amaral, M.M.; Ibarra, C. Endocytosis, Cytotoxicity, and Translocation of Shiga Toxin-2 Are Stimulated by Infection of Human Intestinal (HCT-8) Monolayers With an Hypervirulent. Front. Cell. Infect. Microbiol. 2019, 9, 396. [CrossRef]

26. Sánchez, D.S.; Fischer Sigel, L.K.; Balestracci, A.; Ibarra, C.; Amaral, M.M.; Silberstein, C. Eliglustat prevents Shiga toxin 2 cytotoxic effects in human renal tubular epithelial cells. Pediatr. Res. 2021. [CrossRef]

27. Martin-Ramirez, J.; Hofman, M.; van den Biggelaar, M.; Hebbel, R.P.; Voorberg, J. Establishment of outgrowth endothelial cells from peripheral blood. Nat. Protoc. 2012, 7, 1709-1715. [CrossRef] [PubMed]

28. Feitz, W.J.C.; van de Kar, N.C.A.J.; Cheong, I.; van der Velden, T.J.A.M.; Ortiz-Sandoval, C.G.; Orth-Höller, D.; van den Heuvel, L.P.J.W.; Licht, C. Primary Human Derived Blood Outgrowth Endothelial Cells: An Appropriate In Vitro Model to Study Shiga Toxin Mediated Damage of Endothelial Cells. Toxins 2020, 12, 483. [CrossRef]

29. Bligh, E.G.; Dyer, W.J. A rapid method of total lipid extraction and purification. Can. J. Biochem. Physiol. 1959, 37, 911-917. [CrossRef] [PubMed]

30. Groener, J.E.; Poorthuis, B.J.; Kuiper, S.; Helmond, M.T.; Hollak, C.E.; Aerts, J.M. HPLC for simultaneous quantification of total ceramide, glucosylceramide, and ceramide trihexoside concentrations in plasma. Clin. Chem. 2007, 53, 742-747. [CrossRef] [PubMed]

31. Gold, H.; Mirzaian, M.; Dekker, N.; Joao Ferraz, M.; Lugtenburg, J.; Codée, J.D.; van der Marel, G.A.; Overkleeft, H.S.; Linthorst, G.E.; Groener, J.E.; et al. Quantification of globotriaosylsphingosine in plasma and urine of fabry patients by stable isotope ultraperformance liquid chromatography-tandem mass spectrometry. Clin. Chem. 2013, 59, 547-556. [CrossRef]

32. van de Kar, N.C.; Monnens, L.A.; Karmali, M.A.; van Hinsbergh, V.W. Tumor necrosis factor and interleukin-1 induce expression of the verocytotoxin receptor globotriaosylceramide on human endothelial cells: Implications for the pathogenesis of the hemolytic uremic syndrome. Blood 1992, 80, 2755-2764. [CrossRef]

33. Stricklett, P.K.; Hughes, A.K.; Ergonul, Z.; Kohan, D.E. Molecular basis for up-regulation by inflammatory cytokines of Shiga toxin 1 cytotoxicity and globotriaosylceramide expression. J. Infect. Dis. 2002, 186, 976-982. [CrossRef] [PubMed]

34. Shen, J.S.; Busch, A.; Day, T.S.; Meng, X.L.; Yu, C.I.; Dabrowska-Schlepp, P.; Fode, B.; Niederkrüger, H.; Forni, S.; Chen, S.; et al. Mannose receptor-mediated delivery of moss-made $\alpha$-galactosidase A efficiently corrects enzyme deficiency in Fabry mice. J. Inherit. Metab. Dis. 2016, 39, 293-303. [CrossRef] [PubMed]

35. Silberstein, C.; Copeland, D.P.; Chiang, W.-L.; Repetto, H.A.; Ibarra, C. A Glucosylceramide Synthase Inhibitor Prevents the Cytotoxic Effects of Shiga Toxin-2 on Human Renal Tubular Epithelial Cells. J. Epithel. Biol. Pharmacol. 2008, 1, 71-75. [CrossRef]

36. Silberstein, C.; Lucero, M.S.; Zotta, E.; Copeland, D.P.; Lingyun, L.; Repetto, H.A.; Ibarra, C. A glucosylceramide synthase inhibitor protects rats against the cytotoxic effects of shiga toxin 2. Pediatr. Res. 2011, 69, 390-394. [CrossRef] [PubMed]

37. Abe, A.; Arend, L.J.; Lee, L.; Lingwood, C.; Brady, R.O.; Shayman, J.A. Glycosphingolipid depletion in fabry disease lymphoblasts with potent inhibitors of glucosylceramide synthase. Kidney Int. 2000, 57, 446-454. [CrossRef] [PubMed]

38. Girard, M.C.; Sacerdoti, F.; Rivera, F.P.; Repetto, H.A.; Ibarra, C.; Amaral, M.M. Prevention of renal damage caused by Shiga toxin type 2: Action of Miglustat on human endothelial and epithelial cells. Toxicon 2015, 105, 27-33. [CrossRef] [PubMed]

39. Balwani, M.; Burrow, T.A.; Charrow, J.; Goker-Alpan, O.; Kaplan, P.; Kishnani, P.S.; Mistry, P.; Ruskin, J.; Weinreb, N. Recommendations for the use of eliglustat in the treatment of adults with Gaucher disease type 1 in the United States. Mol. Genet. Metab. 2016, 117, 95-103. [CrossRef]

40. van der Veen, S.J.; Hollak, C.E.M.; van Kuilenburg, A.B.P.; Langeveld, M. Developments in the treatment of Fabry disease. J. Inherit. Metab. Dis. 2020, 43, 908-921. [CrossRef]

41. Karpman, D.; Andreasson, A.; Thysell, H.; Kaplan, B.S.; Svanborg, C. Cytokines in childhood hemolytic uremic syndrome and thrombotic thrombocytopenic purpura. Pediatr. Nephrol. 1995, 9, 694-699. [CrossRef] [PubMed] 
42. Tuttle, J.; Gomez, T.; Doyle, M.P.; Wells, J.G.; Zhao, T.; Tauxe, R.V.; Griffin, P.M. Lessons from a large outbreak of Escherichia coli O157:H7 infections: Insights into the infectious dose and method of widespread contamination of hamburger patties. Epidemiol. Infect. 1999, 122, 185-192. [CrossRef] [PubMed]

43. Pacheco, A.R.; Sperandio, V. Shiga toxin in enterohemorrhagic E.coli: Regulation and novel anti-virulence strategies. Front. Cell. Infect. Microbiol. 2012, 2, 81. [CrossRef] 